\title{
Processo de escolha do livro didático de História numa perspectiva discursiva
}

Process of choosing the History textbook from a discursive perspective

Paula Ricelle de Oliveira, mestranda em Estudos de Linguagens, CEFET-MG, email: pesquisaldcefet@gmail.com

\section{Resumo}

Este artigo investiga o processo de escolha do livro didático de História a partir do ponto de vista dos docentes, no âmbito do PNLD. Como instrumento para coleta das informações foram aplicados questionários. A análise dos dados coletados pauta-se sob a perspectiva discursiva com base no Sistema da Avaliatividade (MARTIN e WHITE, 2005).

Palavras chave: Escolha do livro didático; Discurso docente; Sistema da Avaliatividade.

\section{Abstract}

This article investigates the process of choosing the History textbook from the point of view of teachers, under the PNLD. As instruments for data collection questionnaires were applied. The analysis of the data collected is guided under the discursive perspective based on the Appraisal System (MARTIN and WHITE, 2005).

Keywords: choice of textbook; Teaching speech; Appraisal system. 


\section{Introdução}

O Programa Nacional do Livro Didático (PNLD), criado por meio do decreto $\mathrm{n}^{\circ}$ 91.542 de 1985, estabelece que a escolha do livro didático seja feita diretamente pelo professor, por ser ele o conhecedor da realidade do seu aluno e da escola. Nesse sentido, este trabalho consiste em uma investigação sobre o processo de escolha do livro didático de História, numa perspectiva discursiva, mais especificamente sob o olhar do docente no processo de seleção desse material.

Essa discussão ganha importância na medida em que se insere em um contexto educacional de política de promoção e distribuição gratuita desses materiais por programas do governo que visam prover a democratização do acesso e permanência das classes populares nas escolas. Ao escolher um livro didático, o professor deve considerar as propostas definidas pelo Projeto Político-Pedagógico (PPP) de sua escola e certificar-se que sua escolha atenda à demanda da sua ação pedagógica, da comunidade escolar e do seu público.

Nessa perspectiva, o recorte privilegiado para essa investigação é analisar as atitudes dos professores de escolas públicas no processo de escolha do livro didático de História. Para atingir esse objetivo, foram elencados os seguintes objetivos específicos: descrever os processos de escolha dos livros didáticos nas escolas a partir do ponto de vista dos docentes; identificar e discutir os elementos que influenciam nas escolhas dos livros didáticos pelos professores de História em seus contextos; analisar as avaliações presentes no discurso docente a respeito do processo de escolha de livro didático de História.

Estarão em foco a discussão de dados a respeito do processo de escolha do livro didático de História no âmbito do PNLD/2014 e/ou PNLD/2015 do ponto de vista dos professores. Para debater essa questão, foram utilizados como fonte de informação professores de História, que lecionam no Ensino Fundamental II e Ensino Médio, abrangendo as redes públicas de ensino Municipal, Estadual e Federal, dentro da delimitação territorial de Belo Horizonte e Região Metropolitana.

Como instrumento para coleta de informação, foi utilizado questionário desenvolvido a partir da ferramenta "Formulários" disponível no Google Docs. Esse instrumento, acessível no domínio google.com permite a elaboração, distribuição, coleta e registro das respostas, de maneira descritiva e em gráficos. 0 questionário foi estruturado em duas partes: a primeira contempla a caracterização do docente, com questões sobre formação e atuação dos professores; a segunda parte é composta de questões abertas com foco no processo de seleção do livro didático de História.

A análise dos dados coletados se pauta sob uma perspectiva discursiva com base no Sistema da Avaliatividade (SA) de Martin e White (2005), buscando 
recorrências nos discursos dos docentes das avaliações presentes sobre o processo de escolha.

Este artigo é uma apresentação sintética da pesquisa desenvolvida pela autora no âmbito do mestrado em Estudos de Linguagens do Centro Federal de Educação Tecnológica de Minas Gerais (CEFET-MG), sob a orientação do Prof. Dr. Renato Caixeta da Silva, e encontra-se vinculado ao Grupo de Pesquisa em Materiais e Recursos Didáticos do CEFET/MG.

\section{O sistema da avaliatividade}

O sistema da avaliatividade, desenvolvido a partir dos princípios teóricos da Linguística Sistêmico-Funcional (LSF) (HALLIDAY, 1994), considera a língua como um sistema sócio-semiótico. Em outras palavras ela é interpretada como um sistema de significados. Considerando-se as metafunções da linguagem (ideacional, interpessoal e textual), Martin e White (2005) elaboraram o Sistema da Avaliatividade (SA) que, embora desenvolvido a partir dos fundamentos da LSF, dá conta do modo como os falantes/escritores constroem textualmente a avaliação. $O$ principal objetivo é analisar a avaliação presente na linguagem, a forma como o interlocutor constrói, por meio da linguagem, suas atitudes: afeto, apreciação e julgamento.

No caso do discurso dos professores, o SA pode auxiliar a compreender como esses profissionais apresentam, julgam e avaliam o processo de escolha do livro didático de História. O discurso dos docentes se apropria de certos valores e crenças que são características do ensino de História e do contexto escolar. Desta maneira, a utilização do SA se torna pertinente na medida em que a proposta é analisar a avaliação que o professor faz sobre o processo de seleção e escolha do livro didático.

O SA consiste na construção de significados interpessoais, e referem-se às atitudes negociadas num texto pelos interlocutores, bem como a gradação que sofrem e a fonte (de onde e de quem se originam). Esse sistema oferece recursos para avaliar coisas, o caráter das pessoas e seus sentimentos. Segundo Martin e White (2005) o SA é importante porque revela sentimentos e valores do falante/escritor e, também, porque as avaliações "podem estar relacionadas ao status de autoridade do falante/escritor construído pelo texto" (MARTIN e WHITE, 2005 , p. 2). O SA compõe-se por três subsistemas: atitude, gradação e engajamento.

O subsistema da atitude se subdivide em afeto, julgamento e apreciação. 0 afeto refere-se à expressão de emoção e sentimento, podendo ser positivo ou negativo, e: 


\section{V SILID IV SIMAR

acontecer também na expressão de uma qualidade (epíteto, atributo ou circunstância), um processo, ou um comentário (SILVA, 2012, p. 59).

O julgamento diz respeito à avaliação do caráter de conduta social, aos significados atribuídos ao comportamento humano em relação à ética e à moral estabelecidas e reproduzidas na sociedade. E também pode

[...] ser positivo ou negativo implícito ou explícito no discurso, se referir ao âmbito pessoal (admiração + ou crítica -) e ao âmbito moral (louvação + ou condenação -). No âmbito pessoal, o julgamento encerra uma estima social. Já com relação ao âmbito moral, o julgamento encerra uma sanção social. (SILVA, 2012, p. $60)$.

A apreciação associa-se à avaliação do valor das coisas, entende-se "coisa" numa visão mais ampla, como objeto, instituição, relações, qualidade abstrata, ou seja, o modo como eles são valorizados em determinado campo. Essa apreciação pode ser positiva ou negativa e sofrer variações entre expressão de reações, valorização e composição da coisa apreciada.

As avaliações de atitude podem apresentar níveis de graduação, é possível dizer qual a força do nosso sentimento por alguém ou alguma coisa. O subsistema responsável por essa escolha é o da gradação, que se subdivide em força e foco. A força aumenta ou diminui o grau da atitude expressa, já o foco especifica, aprofunda ou suaviza uma atitude.

O subsistema engajamento é responsável pela fonte da (s) voz (es) do discurso. É por meio desse sistema que os falantes/escritores se posicionam perante o discurso. Quando há uma voz no discurso, caracteriza-se monoglossia, quando o discurso se constitui por múltiplas vozes denomina-se heteroglossia. O esquema abaixo representa uma visão geral dos recursos do Sistema da Avaliatividade apresentado acima e proposto por Martin e White (2005):

$$
\text { Avaliatividade }\left\{\begin{array}{l}
\text { Engajamento }\left\{\begin{array}{l}
\text { Monoglossia } \\
\text { Heteroglossia }
\end{array}\right. \\
\text { Atitude }\left\{\begin{array}{l}
\text { Afeto... } \\
\text { Julgamento... } \\
\text { Apreciação... } \\
\text { Gradação }\left\{\begin{array}{l}
\text { Força } \\
\text { Foco }
\end{array}\right.
\end{array}\right.
\end{array}\right.
$$


Esquema1. Sistema de Avaliatividade. Fonte: Martin e White (2005, p. 38).

\section{O processo de escolha do livro didático de História no discurso dos professores}

A coleta de dados aconteceu no período de novembro de 2014 a abril de 2015; ao todo foram coletados e consolidados 38 questionários ${ }^{1}$. Para alcançar o primeiro objetivo proposto, que consiste em descrever os processos de escolha dos livros didáticos nas escolas a partir do ponto de vista dos professores, foram levantadas questões que dos questionários emergiram. Assim foi possível chegar a algumas conclusões.

Grande parte dos professores (24 deles) reconhece que são os principais responsáveis pela realização da escolha da obra. Também compreendem a importância da participação do professor no processo de escolha do livro. Contudo, 11 informantes relatam a ocorrência de professores que desconsideram esse momento, logo, deixando de atuar como protagonista do processo de escolha do livro. Isso acontece, em grande parte, devido ao pouco tempo para realizarem essa atividade e por acreditarem que não receberiam o livro escolhido.

Há ainda a descrição de 03 professores que foram silenciados pela sua situação funcional. Por estarem na escola em regime de contrato temporário, a sua permanência na escola para o próximo ano (no qual iniciaria o uso do livro didático selecionado) não estava garantida como a dos outros docentes que possuíam estabilidade profissional, logo não tiveram voz ativa no momento de decidir qual obra seria adotada.

No corpus, 05 professores relatam que acreditam que o livro didático já estava (pré) selecionado, seja pelo Estado ou Secretária de Educação da rede onde atuam. Ao encontro dessas informações, 04 docentes afirmam que não receberam (ou não recebem) a obra de sua preferência, e acreditam que isso acontece por questões políticas.

Uma das reclamações mais recorrentes dos informantes se deve ao tempo disponível para a realização da análise e escolha do material, seja pelo próprio período estabelecido pelo PNLD ou mesmo por falta de planejamento da escola. Essa contestação foi observada na resposta de 10 respondentes.

Mesmo diante dos relatos dos informantes de que há pouco tempo para realizar a escolha, 18 docentes afirmam que as escolas utilizam pelo menos um encontro para discutir a escolha do livro, seja com todo corpo docente ou separados por disciplina.

Quanto às ações que são desenvolvidas por parte da equipe gestora da escola, 04 professores relatam que coube a esses sujeitos promoverem a organização e orientação para a escolha do livro. Contudo, outros 04 informantes reclamaram sobre a falta de ação desses sujeitos. 
Após expor os primeiros dados que emergiram dos relatos dos docentes, outro objetivo aqui proposto consiste em identificar e discutir os elementos que influenciam nas escolhas dos livros didáticos pelos professores de História em seus contextos. Essa era uma pergunta especifica do questionário e configurava-se em questão aberta, possibilitando ao respondente abordar questões peculiares que remetem aos contextos diferenciados e com pluralidade da realidade da prática do exercício profissional.

Assim, com os dados coletados, foi possível chegar às seguintes conclusões: 16 respondentes afirmaram que analisam as atividades presentes no livro didático, seja pelo volume, tipo, qualidade ou adequação à realidade e/ou nível dos discentes; 14 deles levam em consideração a adequação da linguagem dos livros ao nível educacional dos alunos; 11 professores afirmaram considerar determinante a presença de variedade de recursos didáticos que compõem as obras, como mapas, documentos e mais expressivamente o uso de imagens.

Em menor proporção, 06 professores citaram que observaram quais conteúdos foram privilegiadas no livro; 05 consideram a qualidade gráfica da obra como tipo e tamanho da fonte; 03 contemplam a adequação da obra à realidade dos alunos; 02 analisam se o livro atendia às propostas do Currículo Básico Comum (CBC) da escola; 02 apreciam alguns conteúdos em especifico, como diversidade brasileira e História africana e indígena; 02 observam a clareza na organização dos conteúdos; 02 analisam atualização dos conceitos e pertinência histórica; 01 se 0 livro do professor apresentava algum recurso extra; 01 tempo da editora no mercado; 01 comparação da análise dos pareceristas.

É importante observar nesses dados, que quase todos os professores contemplam o tipo de linguagens (seja verbal e não verbal) utilizadas nas obras, esse dado mostra a importância do uso desse recurso para a compreensão do aluno no conteúdo abordado no livro didático. Os professores parecem ter consciência de que é por meio da linguagem que se adquire o conhecimento necessário, o que pode configurar o livro didático de História como um importante meio de ensino/aprendizagem dos recursos linguísticos disponíveis na sociedade.

Em outro momento, os docentes foram questionados sobre quais elementos foram consultados para a escolha do livro didático, tendo como opções: Guia do livro didático; Manual do professor; Consulta ao livro didático; Conversa com os colegas; Consulta à coordenação pedagógica; Catálogo ou outros materiais impresso da editora; Conversa com representantes de editora; e Outros. O professor podia marcar todas as opções da lista que realmente utilizou na escolha do livro, assim, dos 27 professores que responderam essa questão foi possível obter os seguintes resultados:

- Consulta ao livro didático: 23

- Conversa com os colegas: 23 
- Guia do livro didático: 16

- Manual do professor: 12

- Catálogo ou outros materiais impresso da Editora: 06

- Conversa com representante de editora: 04

- Outros: 04

- Consulta a coordenação pedagógica: 02

- Conversa com autores: 02

A opção "Outros" foi preenchida com as seguintes alternativas; consulta ao cd do livro didático com conteúdos digitais; debate entre os membros da comissão interna de avaliação (Rede Federal); atividade proposta pelo livro didático; e visita ao site do PNLD.

Antes de avançar, vale a pena observar a necessidade que os professores têm de consultar a obra de sua preferência; esses dados vêm ao encontro de outros trabalhos (QUEIROZ, 2012); (FERNANDES, 2013). Contudo, vale ressaltar que o acesso diretamente dos professores ao livro didático não é uma ação prevista pelo PNLD, o envio de obras para as escolas consiste no resultado de investimentos das editoras na divulgação de exemplares, o que pode acarretar no privilégio de algumas editoras em detrimento das outras que não possuem grande poder de propagação, já que os professores baseiam suas escolhas nas obras disponíveis para consulta no momento da escolha (TERRAZZAN e ZAMBON, 2013).

Dados idênticos foram obtidos na opção 'conversa com os colegas'; isso se deve ao fato de que, dentro do PNLD, para realizar a escolha do livro didático se faz necessário a participação de todos os professores, com objetivos claros de discutir e chegar ao consenso da melhor obra a ser adotada mediante as necessidades da escola, por isso, um número expressivo de professores que optaram por esse elemento. Também, essa ocorrência remete à procura de um apoio, a opinião de outro profissional que auxilie na escolha, como aponta a pesquisa de Silva (2010).

Muito se pode inferir desses dados, aqui apenas foram sintetizados os elementos mais significativos para a contribuição desse estudo. Passa-se, agora para o ultimo objetivo desse trabalho que consiste em analisar as avaliações presentes no discurso docente a respeito do processo de escolha de livro didático de História.

Assim, após analisar, com base no Sistema da Avaliatividade, a resposta dos 38 professores quanto à avaliação que fazem dos processos de escolha do livro didático de Historia, surgiram as três categorias que correspondem aos três subsistemas da teoria adotada para o estudo: atitude, engajamento e gradação. 0 maior número de registro foi constatado no subsistema atitude, seguido de gradação e força. 
Esses dados, traduzidos em números, representam 370 casos de atitude, 182 casos de gradação e, 178 casos de engajamento. A partir disso, podemos afirmar que os professores avaliaram os processos de escolha do livro didático de História em suas escolas sob um ponto de vista positivo e/ou negativo.

Foi possível obter certo equilíbrio de avaliações positivas e negativas dentro do subsistema atitude. A expressão de sentimentos negativos presente no corpus pode estar ocorrendo devido a várias queixas levantadas pelos informantes que complica ou até mesmo compromete o momento de escolha do livro didático. Já as avaliações positivas estão presentes em virtude da grande parte dos respondentes reconhecerem a importância desse momento.

Quanto à gradação, muitos professores, ao emitirem suas expressões, preferiram aumentar ou diminuir o grau de avaliação Isso pode estar acontecendo devido à necessidade de graduar aumentando ou intensificando ações e acontecimentos com o objetivo de tornar relevante o que está sendo escrito, de alertar o leitor para fatos que não deveriam ser rotineiros.

Por ultimo, no engajamento predominou a monoglossia, ou seja, os professores realizaram suas avaliações expressando o seu ponto de vista, isso se deve a conjuntura das perguntas solicitadas, que exigia do respondente sua opinião quanto ao processo de escolha do livro.

\section{Algumas conclusões}

A proposta de analisar o processo de escolha do livro didático de História sob o ponto de vista do professor leva a inferir que ao realizar essa atividade o professor precisa superar diversos obstáculos, alguns deles extrapolam suas funções e outros nem estão ao seu alcance. Isso faz com que os professores expressem sentimentos de insatisfação, e alguns deixem de atuar como os principais protagonistas desse processo.

Os docentes, muitas das vezes, utilizam de estratégias diferenciadas das propostas pelo PNLD, o que nos leva a pensar que esse Programa precisa rever algumas das suas orientações. É preciso entender que se há a necessidade do professor consultar a obra é necessário propor ações que viabilizem essa prática.

Com o embasamento no SA foi possível observar a avaliação construída textualmente no discurso desses professores sobre o processo de escolha do livro didáticos de História, considerando as peculiaridades da realidade de cada profissional. Depreende-se, então, que os docentes expressam suas atitudes negativas devido à realidade complexa em que acontece o processo. Contudo, ao reconhecer a importância desse momento apresentam avaliações positivas.

Apesar dos limites dessa exposição, ela se constitui um registro sobre o processo de escolha do livro didático de História. As reflexões aqui apresentadas não esgotam o assunto, pois não compreendem todas as complexas questões sociais, culturais, econômicas e educacionais que envolvem as escolhas e as 
avaliações dos professores, muito pelo contrário, ela deve despertar e apontar caminhos para novas perspectivas que levem a melhor elucidação do assunto.

\section{Referencias bibliográficas}

BRASIL, Ministério da Educação (FNDE). Resolução no 42 de 28 de agosto de 2012. Dispõe sobre o Programa Nacional do Livro Didático (PNLD) para a educação básica.

FERNANDES, Magda Carvalho. O acesso ao livro didático de História no Programa Nacional do Livro Didático, dos anos iniciais do Ensino Fundamental, entre 1999 e 2008. in: VII Congresso Brasileiro de História da Educação, 2013, Cuiabá. Circuitos e Fronteiras da História da Educação no Brasil, 2013. v. 1. p. 1.

HALLIDAY, M.A.K. An Introduction to Functional Grammar. 2 ed. London: Arnold, 1994.

MARTIN, Jim. R.; WHITE, Peter. The language of evaluation: Appraisal in English. New York: Palgrave, 2005.

QUEIRÓZ, Carolina Penafiel de. Só quero saber do que pode dar certo, não tenho tempo a perder: escolhas e usos dos livros didáticos de História em escolas municipais. Rio de Janeiro, 2012. 171 p. Dissertação de Mestrado Departamento de Educação, Pontifícia Universidade Católica do Rio de Janeiro.

SILVA, Renato Caixeta. Avaliação e seleção de livros / materiais didáticos para o ensino de línguas - relato de uma oficina. In:. Anais do II SILID / I SIMAR. Rio de Janeiro: PUC-Rio, Edição Entrelugar. 2010. p. 53-63.

SILVA, Renato Caixeta da. Representações do livro didático de inglês: análise dos discursos de produtores e usuários com base na Linguística Sistêmico-Funcional. Rio de Janeiro, 2012. 332 p. Tese de Doutorado Departamento de Letras - Pontifícia Universidade Católica do Rio de Janeiro.

TERRAZZAN, Eduardo Adolfo e ZAMBON, Luciana Bagolin. Política de material didático no Brasil: organização dos processos de escolha de livro didático em escolas públicas de educação básica. Revista Brasileira de Estudos Pedagógicos, v. 94, n. 237. p. 584-602, maio/ago. 2013.

${ }^{1}$ Não foram excluídos, da amostra, professores que não participaram do processo de escolha do livro didático de História, pois consistia em outro objetivo da pesquisa 
entender quais os motivos levaram esses profissionais a não participarem desse momento, e tendo em vista que ao utilizar a obra, esses profissionais são capazes de expressar suas avaliações quanto a sua adequação a realidade da escola e dos alunos, bem como o docente poderia estar presente na escola e não ter participado, ambos os casos ocorreram na pesquisa. Dessa forma, dos 38 participantes da pesquisa, 11 se enquadram nessa modalidade. 